nuestro teatro áureo y su inabarcable magnitud. Lope, Tirso, Calderón, Alarcón, Vélez de Guevara, Moreto y muchísimos más, son autores que, nunca se dirá bastante ni con la suficiente intensidad, constituyen la pléyade más rica y poderosa de todo el teatro universal, y no es inútil chovinismo afirmarlo sino justicia y conocimiento. Esperemos que esta magnífica aportación sobre Rojas que nos presenta ahora el profesor Pedraza, y la que nos promete todavía, sea algo más que una esperanza para el reconocimiento y sobre todo mayor valoración de uno de los mejores artífices del mismo.

\section{ENRIQUE RULL}

RIBERA Llopis, J. M., Projecció i recepció hispàniques de Caterina Albert i Paradis, «Víctor Català», $i$ de la seva obra. Girona, CGC Edicions, 2007. 342 págs.

Quizá no sea necesario decirlo o no se debe decir: parece que la figura de Caterina Albert i Paradís, "Víctor Català» (1869-1996), ha adquirido ya distancia suficiente en el tiempo como para ser estudiada, analizada y juzgada más allá de las páginas canónicas que se le han dedicado. $\mathrm{Su}$ valor estético y literario continúa vigente - es decir, discutido: un síntoma de vitalidad, a fin de cuentas- pero más de cien años transcurridos desde Solitud (1905) y unas cuantas décadas desde la publicación del grueso de su obra dan para establecer un punto medio y virtuoso. En este proceso no se queda al margen (y reconforta en un país de fuertes ingratitudes) la iniciativa que se lleva a término desde l'Escala natal de la autora, uno de cuyos frutos es la monografía que ahora tenemos la oportunidad de leer y reseñar.
El trabajo del Dr. Ribera Llopis tiene, de entrada, dos méritos indiscutibles. El primero, la minuciosidad documental, que aporta muchas noticias jugosas y prácticamente inéditas, como veremos enseguida. El segundo, plantear de forma explícita una pregunta que nadie debe eludir: ¿por qué no teníamos hasta ahora una obra como ésta? Sabemos, y la experiencia diaria debería recordárnoslo por si lo olvidamos entre esquemas didácticos y otras palabrejas esdrújulas, que no nos rodean tradiciones exclusivamente verticales. Además, en el ámbito de la catalanística, se han documentado muy bien las relaciones «hispánicas» de autores como Narcís Oller o Joan Maragall. Quizá puedan haber pesado, en el caso de Víctor Català, algunos factores diferentes de la tozudería (la carpetovetónica y la otra) contra la que el Dr. Ribera Llopis arremete con firmeza y razón a lo largo de su escrito. O más allá de la posible decadencia de la metodología comparatista, superada por los bricolages estructurales - los cuales, dicho sea de paso, aparte de estar ya demodés, pueden dar buenos resultados en manos de los jefes de filas de la investigación filológica, pero en otras manos menos sensatas han llenado el mercado de la alta divulgación con mucha estolidez vacía de finalidad y llena de palabrejas que aparentan cientifismo-. Nosotros, con la osadía de las primeras impresiones, incluso nos arriesgaríamos a sugerir un par de motivos adicionales. Los altibajos en la consideración histórica de la autora, por ejemplo, a pesar de unos tonos de alabanza que a veces no encerraban más que el simple respeto debido; o una cierta miopía no del todo injustificable que ha hecho pasar durante mucho tiempo a Víctor Català por una escritora unius libri. Ítem más, a la vista del libro que comentamos, quizá añadiésemos que, a pesar de la ilustre cate- 
goría de sus principales corresponsales en castellano - la condesa de Pardo Bazán, Concha Espina, Blanca de los Ríospuede que no se trate de nombres tan sonoros al oído del aficionado como los de Galdós o Unamuno; o sean materia reservada desde los propios ambientes académicos, no sin displicencia, al coto para algunos vedado de la ginocrítica.

Queda claro, no obstante, que este libro es mucho más que sus dos méritos principales: ya hemos adelantado una referencia a su ingente, bien trabajada documentación. A partir sobre todo del epistolario de la autora ampurdanesa, Ribera Llopis construye dos capítulos iniciales que, sin lugar a dudas, serán los que más interesen al lector culto no especializado. De una forma que él mismo califica como «narrativa», aparecen ante nuestros ojos los aspectos públicos y privados de las relaciones establecidas más allá de Cataluña (no siempre «Castilla adentro») por Caterina Albert. Un horizonte receptivo que, con las limitaciones documentadas, nace indiscutiblemente del prestigio personal, pero también de la atención generada en el resto del Estado por la eclosión de las letras catalanas a partir de la Renaixença, de forma muy especial durante el cambio de siglo y hasta el inicio de la Guerra Civil en 1936. Es un interés que no siempre podremos llamar catalanófilo stricto sensu, que variará como era esperable después de la contienda, a pesar que siempre se manifestarán unas pocas lealtades inquebrantables hasta la muerte. Sobre tal horizonte, Víctor Català se proyecta con coherencia, manteniendo con una humildad tópica su adhesión a la lengua catalana pero sin perder las oportunidades de ser traducida, de autotraducirse o de escribir a veces originales en castellano; junto con unas ideas de concordia ibérica compartidas por más de un corresponsal - y muy significativamente con Maximiano García Venero.

Este nombre que acabamos de citar, por cierto, será sin duda uno de los muchos descubrimientos agradables que esperan al que se acerque a las páginas de este estudio. Porque la mejor aportación al lector de estos dos primeros capítulos consiste, más que no en dibujar un panorama más o menos intuible, en el rescate de figuras poco divulgadas, en hacerlas presentes con el papel que representaron durante el diálogo, con todos los matices. En algunos de ellos incluso podemos ver de qué forma - por ser catalanoparlantes de origen o buenos conocedores de la lengua- el contacto con una autoridad como Víctor Català los impulsa al cultivo escrito i activo del catalán. Es el caso de catalanes emigrados a América, como el impagable Domingo Brunet, o el del ferviente admirador valenciano — permita el paciente lector tamaño sentimentalismo local del que firma- Francisco Cantó i Blasco. Una nómina entera de autores, periodistas y estudiosos bastante significados en su época por una actitud favorable al diálogo y la integración entre las diversas literaturas de España, que hará caer más de un prejuicio y cuya recuperación debemos a la tenacidad intachable del investigador.

Tras este inicio «narrativo» tan documentado, el libro concluye con dos apartados catalográficos que a partir de ahora deberían convertirse en un punto de referencia fundamental para el estudioso o el estudiante aplicado. Aunque apuntando algunas cuestiones no resueltas, Ribera Llopis establece y documenta en el primero de estos apartados hasta las aportaciones de ultimísima hora por lo que respecta a la recepción crítica de Víctor Català en el mundo cultural de expresión castellana; mientras que en el segundo estudia por orden cronológico las traducciones, autotra- 
ducciones y originales castellanos de la narradora. No se trata de una mera sistematización de los documentos vistos o transcritos en las páginas precedentes: son páginas que aclaran y corrigen apreciaciones poco afinadas de algunas investigaciones anteriores, con un efecto de conjunto bien estructurado y ameno, como los hoy escasos buenos libros de texto.

Sumemos, para ir acabando, un importante apéndice documental que reproduce en facsímil una selección de los documentos utilizados, y quizás ya entenderán por qué no necesitamos hacer ningún elogio más. Eso sí, y sin demérito para el autor: es lástima que una edición como ésta - de factura material simpática y modesta, antítesis del mamotreto universitario - y tratándose de un texto tan fundamentado y fundamental, se produzcan aquí y allá ligeros descuidos ortotipográficos que dificultan la lectura. Dicho sea con castidad y perdón de la mesa.

\section{RAúl HERnÁNDEZ CABALlER}

Rojas Zorrilla, Francisco de, Obras completas, volumen I. Primera parte de comedias. Edición crítica y anotada del Instituto de Teatro Clásico, dirigida por Felipe B. Pedraza Jiménez y Rafael González Cañal. Coordinadora del volumen: Elena E. Marcello. Cuenca, Ediciones de la Universidad de Castilla-La Mancha, 2007, 773 págs.

A diferencia de los grandes dramaturgos del Siglo de Oro, como Lope de Vega y Calderón, la obra de Rojas, que también contó con el aplauso del público de la época y los elogios de la crítica en los momentos de mayor auge de la comedia (1630-1640), se vio progresivamente olvi- dada a medida que avanzaban los siglos. Todavía en el siglo XVIII, los neoclásicos admitieron una parte de su obra, la considerada de mayor comicidad o de intencionalidad moral, pero desde el siglo XIX la obra y su autor fueron arrinconados. Sólo algunos títulos podían leerse en las colecciones de clásicos preparadas por Ortega (1827-28), Eugenio de Ochoa (1838) y Mesonero Romanos en la BAE (1861). Esta última edición, que contenía 31 dramas, ha sido durante muchos años en reediciones posteriores la única vía que hemos tenido para leer a Rojas. El escaso interés por sus obras iba paralelo a la consideración de su autor, definido por tópicos que tuvieron la fortuna de repetirse durante siglos sin que nadie tratase de averiguar cuál era la verdad o falsedad de los mismos. Se prescindió de las importantes aportaciones que Rojas había realizado a la dramaturgia y se olvidaron sus innovaciones en la técnica, en la escena y en la originalidad de su creación en los espacios dramáticos. Sólo en los albores del siglo XX, cuando los clásicos se trataron de vivificar, Rojas se convirtió en tema de estudio, o al menos de interés, y pudieron rescatarse del olvido sus obras. Primero, con la importante aportación documental de Cotarelo y después, con el intento de organizar la obra y de estudiarla por parte de MacCurdy, ya a mediados de siglo. A sus investigaciones se fueron sumando, aunque tímidamente, otras después de muchos años de silencio sobre el dramaturgo toledano.

Ahora, cuando se han cumplido cuatrocientos años del nacimiento del autor, y gracias al empeño de los profesores Felipe Pedraza y Rafael González Cañal, ayudados por un amplio equipo de investigadores, y financiados por diferentes proyectos de Investigación del Ministerio de Ciencia y Tecnología, a través de la Uni- 